Reprod. Nutr. Dévelop., 1988, 28 Suppl. n 1, 85-86

\title{
Effets de l'addition de palmitostéarine ou d'huile de soja sur les protozoaires du rumen chez la vache laitière et chez le mouton
}

D. BAUCHART, Françoise LEGAY-CARMIER; J. P. JOUANY $\left({ }^{*}\right)$, Brigitte MICHALETDOREAU $\left({ }^{* *}\right)$, M. DOREAU $\left({ }^{* *}\right)$

avec la collaboration technique de Christiane LEGAY et de Françoise DUBOISSET

Laboratoire d'Etude du Métabolisme Energétique.

$\left(^{*}\right)$ Unité de la Digestion Microbienne.

(**) Laboratoire des Aliments.

$\left(^{* *}\right)$ Laboratoire de la Lactation, I.N.R.A., Theix, 63122 Ceyrat, France.

Summary. Addition of unprotected palmitostearin ( $P ; 10.6 \% \mathrm{DM}$ intake) or soyabean oil (SO ; $8.7 \% \mathrm{DMI}$ ) to a hay/diet concentrate $(50 / 50)$ led to no significant differences in the total number of protozoa in rumen liquid of dairy cows and sheep, and in the distribution and postprandial variations of protozoan species. Chemical analysis of purified protozoa revealed no significant effects of lipid supplementation on their total N, RNA and lipid contents. However there was a specific incorporation $(P<0.05)$ of $C 16: 0$ and C18: 2 acids in the free fatty acid fraction with the P and SO diets respectively.

L'addition d'huile de lin non protégée (6-8\% MS) riche en C18:3 (60\%) provoque chez le Mouton une très forte réduction du nombre de protozoaires du contenu de rumen (Czerkawski et al., 1975 ; lkwuegbu et Sutton, 1982). Nous avons comparé chez la Vache laitière et chez le Mouton les effets de l'addition de 2 huiles riches en acides gras saturés (palmitostéarine) ou polyinsaturés de type C18: 2 (huile de soja) sur le nombre et la distribution des protozoaires du rumen ainsi que sur leur composition chimique, notamment en acides gras.

Matériel et méthodes. Trois vaches laitières Pie noires et 3 moutons Texel castrés, tous munis d'une canule du rumen, ont reçu en carré latin $3 \times 3$ un régime témoin $(T)$ constitué de foin et de concentré $(50 / 50)$ et le même régime contenant par rapport à la matière sèche ingérée $8,7 \%$ d'huile de soja $(\mathrm{Sj})$ ou $10,6 \%$ de palmitostéarine $(P)$. Le comptage des protozoaires a été effectué sur tous les animaux et pendant 2 jours consécutifs à partir de $5 \mathrm{ml}$ de liquide de rumen prélevés $1 / 2 \mathrm{~h}$ avant et $1,3,5$ et $7 \mathrm{~h}$ après la distribution du repas du matin. La purification des protozoaires a été effectuée par décantation à $40^{\circ} \mathrm{C}$ chez les seules vaches laitières à partir de $10 \mathrm{I}$ de jus de rumen prélevés $7 \mathrm{~h}$ après la distribution du repas. Les teneurs en N, ARN, lipides et acides gras totaux des protozoaires ont été déterminées selon des méthodes décrites par Bauchart et al. (1986).

Résultats et discussion. Pour les 3 régimes étudiés $(T, S j, P)$, le nombre total de protozoaires (moyenne des 5 points horaires) dans le liquide du rumen n'est pas significativement différent chez la Vache laitière $\left(109,115\right.$ et $\left.111.10^{3} / \mathrm{ml}\right)$ comme chez le Mouton $\left(115,157\right.$ et $\left.119.10^{3} / \mathrm{ml}\right)$ ce qui est compatible avec l'absence de réduction de la digestibilité de la matière organique dans le rumen (Doreau et al., non publiés). La distribution des espèces de protozoaires se 
caractérise par la prépondérance des Oligotriches de genre Entodinium spp. (70 à $86 \%$ ) et très secondairement par des Holotriches de genre /sotricha spp. et Dasytrichaspp. (12 à $25 \%$ ) quel que soit le régime ou l'espèce animal considéré. L'amplitude des variations inter et intra-animaux des valeurs mesurées sont 2 à 3 fois plus élevées chez la Vache laitière que chez le Mouton. Pour les 3 régimes et les 2 espèces animales, le nombre de protozoaires baisse de $33 \% 3 \mathrm{~h}$ après la distribution du repas puis reste constant pendant les $4 \mathrm{~h}$ suivantes. Cependant, dans le cas des vaches laitières et pour les 3 régimes, on observe une augmentation de $29 \% 1 \mathrm{~h}$ après la distribution du repas.

Les teneurs en N, ARN, lipides et acides gras totaux des protozoaires chez la Vache laitière ne sont pas modifiées par la nature et la teneur en acides gras des aliments soit $39,9,9,4,28,3$ et $17,6 \mathrm{mg} / \mathrm{g}$ MS respectivement. Parmi les lipides majeurs des protozoaires (phospholipides, $\mathrm{PL}, 54,3 \%$; acides gras libres, $A G L$, $19,3 \%$ ), seule la fraction AGL est directement influencée par les acides gras des régimes $P$ et $S j$ : I'augmentation de 15 et $40 \%$ des teneurs en $\mathrm{C} 16: 0$ (rég. $P$ ) et C18: 2 (rég. Sj) des AGL (tabl. 1) s'explique probablement par l'ingestion de bactéries riches en $A G L$ dont la composition est très marquée par les $A G$ alimentaires (Bauchart et Legay-Carmier, données non publiées) et/ou l'ingestion d'acides gras alimentaires absorbés aux particules des régimes. On ne peut exclure enfin la possibilité d'absorption directe d'AGL alimentaires issus de la lipolyse microbienne sur les protozoaires.

TABL. 1. - Teneur (\% MS) en acides gras totaux et proportion centimésale des principaux acides gras dans la ration témoin $(\mathrm{T})$. l'huile de soja $(\mathrm{Sj})$, la palmitostéarine $(\mathrm{P})$ et des fractions AGL et $P L$ des protozoaires purifiés à partir du contenu du rumen de vaches laitières $(\mathrm{n}=3)\left({ }^{*}: \mathrm{P}<0,05\right)$.

\begin{tabular}{|c|c|c|c|c|c|c|c|c|c|}
\hline \multicolumn{5}{|c|}{ Aliments } & \multicolumn{5}{|c|}{ Protozoaires } \\
\hline Régime & T & $\mathrm{Sj}$ & $P$ & $\mathrm{~T}$ & $\begin{array}{c}\mathrm{AGL} \\
\mathrm{Sj}\end{array}$ & $\mathrm{P}$ & $\mathrm{T}$ & $\begin{array}{l}\mathrm{PL} \\
\mathrm{Sj}\end{array}$ & $\mathrm{P}$ \\
\hline$A G$ totaux & 1,62 & 8,71 & 10,62 & 0,49 & $0,70^{*}$ & 0,50 & 1,20 & 1,35 & 1,30 \\
\hline $\begin{array}{l}\text { C16:0 } \\
\text { C18:0 } \\
\text { C18: } 1 \\
\text { C18:2 }\end{array}$ & $\begin{array}{c}19,9 \\
2,6 \\
12,7 \\
25,4\end{array}$ & $\begin{array}{c}12,1 \\
3,7 \\
18,8 \\
50,1\end{array}$ & $\begin{array}{c}48,4 \\
4,6 \\
24,4 \\
12,3\end{array}$ & $\begin{array}{c}42,0 \\
12,3 \\
9,7 \\
11,9\end{array}$ & $\begin{array}{c}40,1 \\
10,0 \\
12,0 \\
16,7^{*}\end{array}$ & $\begin{array}{c}48,1^{*} \\
9,2^{*} \\
14,5^{*} \\
12,9\end{array}$ & $\begin{array}{c}49,0 \\
5,1 \\
11,6 \\
8,0\end{array}$ & $\begin{array}{c}48,0 \\
4,7 \\
12,0 \\
9,0\end{array}$ & $\begin{array}{c}51,0 \\
3,5 \\
15,0^{*} \\
9,0\end{array}$ \\
\hline
\end{tabular}

Nos résultats montrent que l'ingestion d'acides gras saturés ou polyinsaturés de type 18: 2 n'exerce pas sous forme de triglycérides d'effet défaunant significatif chez le Ruminant, contrairement aux résultats obtenus par Broudiscou et al. (1988) avec des rations supplémentaires en hydrolysat d'huile de soja. Par ailleurs, ces matières grasses ne modifient ni le faciès ni la composition des protozoaires du rumen hormis un effet propre sur leur composition en AGL.

Bauchart D., Legay-Carmier F., Doreau M., Jouany J. P., 1986. Reprod. Nutr. Dévelop., 26, 309-310. Broudiscou L., Van Nevel C. J., Demeyer D. I., Jouany J. P., 1988. Reprod. Nutr. Dévelop. 28, $159-160$.

Czerkawski J., Christie J. W., Breckenridge G., Hunter M. L., 1975. Br. J. Nutr., 34, $25-44$

Ikwuegbu O. A., Sutton J. D., 1982. Br. J. Nutr., 48, 365-375. 